\title{
Correction to: Microplastic sampling techniques in freshwaters and sediments: a review
}

\author{
Nastaran Razeghi ${ }^{1} \cdot$ Amir Hossein Hamidian ${ }^{1,2}\left(\right.$ C) Chenxi Wu $\mathbf{u}^{3,4} \cdot$ Yu Zhang ${ }^{2,4} \cdot$ Min Yang $^{1,2,4}$
}

Published online: 31 August 2021

(c) Springer Nature Switzerland AG 2021

Correction to: Environmental Chemistry Letters

https://doi.org/10.1007/s10311-021-01227-6

In the original publication of the article, the affiliations of the authors were provided incorrectly, and the correct affiliations are provided in this correction.

Publisher's Note Springer Nature remains neutral with regard to jurisdictional claims in published maps and institutional affiliations.

The original article can be found online at https://doi.org/10.1007/ s10311-021-01227-6.

Amir Hossein Hamidian a.hamidian@ut.ac.ir

1 Department of Environmental Science and Engineering, Faculty of Natural Resources, University of Tehran, P.O. Box 4314, 31587-77878 Karaj, Iran

2 State Key Laboratory of Environmental Aquatic Chemistry, Research Center for Eco-Environmental Sciences, Chinese Academy of Sciences, Beijing 100085, People's Republic of China

3 State Key Laboratory of Freshwater Ecology and Biotechnology, Institute of Hydrobiology, Chinese Academy of Sciences, Wuhan 430072, People's Republic of China

4 University of Chinese Academy of Sciences, Beijing 100049, People's Republic of China 